\title{
Exploring the Role of Customer Education on Counterfeiting of Fashion Accessories in the Ghanaian Fashion Industry
}

\author{
Victoria Abra Honu ${ }^{1 *}$ Pearl Yaa Abrafi Manu ${ }^{2 *}$ Deladem Ephraim-Etsey ${ }^{3 *}$ \\ 1. School of Fashion and Design, BlueCrest University College. P.O.BOX AN 18392, Kokomlemle, \\ Ghana \\ 2. Department of Fashion and Design, NVTI, Dansoman Ghana \\ 3. School of Fashion and Design, BlueCrest University College. P.O.BOX AN 18392, Kokomlemle, \\ Ghana \\ * E-mail of the corresponding author: E-mail: vichyie11@gmail.com
}

\begin{abstract}
Within the global marketplace, the production and consumption of counterfeit goods represents a serious social problem. Scholars continue to suggest anti-counterfeit education as a means to resolve this global problem and curb the demand for counterfeit goods, but no scholarly research has empirically evaluated the effectiveness of anti-counterfeit education. Therefore, the purpose of this study is to draw upon such suggestions within the literature, and quantitatively assess the effectiveness of anti-counterfeit education on consumers' perceived knowledge, attitudes, and purchase intentions of fashion counterfeit goods.

This study sought to further test this enquiry by quantitatively assessing very key objectives. The study was conducted using Accra Business District and Osu as the case study. As many as One Hundred (100) respondents were selected using the purposive sampling technique. This was employed because the researcher was particular about the exact respondents needed to respond to the study objectives.

Findings from this study provide relevant implications toward academicians, government officials, fashion retailers, and anti-counterfeiting organizations, such as how to develop effective anti-counterfeit educational content. Such parties with a vested interest in deterring the demand of fashion counterfeit goods should focus on formulating and implementing anti-counterfeit educational tools, such as campaigns and advertisements, which focus on the negative factors and consequences associated with the fashion counterfeit industry.
\end{abstract}

Keywords: anti-counterfeiting, counterfeiting, accessories, consumer, fashion

DOI: $10.7176 / \mathrm{ADS} / 93-05$

Publication date:June $30^{\text {th }} 2021$

\section{Introduction}

Nearly every consumer has come across counterfeited products in one way or another, even if they were not aware of it at the time. Tourist destinations, the internet, and even mainstream distribution channels all over the world have become prime markets for knock-off products or accessories and consumer demand continues to grow. Whether it is termed knock-off, replica, counterfeit, or even the most obvious of terms: fake; it is all referring to the same rising phenomenon of imitated products. The issue of counterfeiting has spread in recent years across many industries. Sports equipment, computer software, car parts, and even prescription drugs are being imitated and sold at a fraction of the price of the originals. This is causing legitimate firms and genuine brand marketers a great deal of frustration.

Whiles according to Ellis (2011) as much as over \$260 million in counterfeited products were seized in 2009 within the United States alone, a figure that has been on the rise for many years; Trade in counterfeit goods has reached $\$ 600$ billion annually on a worldwide basis, while counterfeiting has been estimated to cost business's in the approximately $\$ 250$ billion each year (Norum and Cuno, 2011). Among those most impacted by counterfeiting are firms in the fashion industry, particularly high end fashion brands such as Louis Vuitton, Gucci, and Prada (Mavlanova and Benbunan-Fich, 2010). Due to the relative ease of manufacturing imitated clothing, bags, shoes, and fashion accessories, combined with the prestige and exclusivity achieved through expensive brand marketing campaigns, the fashion industry has become a viable target for counterfeiters all over the world (Mavlanova and Benbunan-Fich, 2010

Such rapid growth of the counterfeit market has emerged as a danger to world trade, while imposing economical and societal threats such as the loss of jobs and legitimate revenue (Ha and Lennon, 2006). A major explanation for the rapid growth in this problem is due to the increase in consumer demand for counterfeit fashion accessories.

Although a thorough body of literature regarding counterfeit fashion accessories currently exists, scholars such as Kim and Karpova (2010) indicated that many of the previous studies have addressed counterfeiting of fashion accessories as it pertains to the supply dimension. The supply dimension of 
counterfeiting of fashion accessories refers to the production and distribution of such goods. Kim and Karpova (2010) explained that the supply dimension has been investigated by examining legal policies and industry efforts to limit the production of such counterfeit fashion accessories. Conversely, academicians have more recently begun to investigate the demand side of the problem (Bian and Veloutsou, 2007; Kim and Karpova, 2010; Koklic, 2011; Norum and Cuno, 2011). Whiles examining demand, scholars have questioned why consumers purchase counterfeit fashion accessories. Researchers have identified that consumers purchase counterfeit fashion accessories because of the affordable prices associated with such goods (Ang et al., 2001; Kozar and Marcketti, 2011).

Previous studies have also identified significant factors of influence toward consumers' attitude and intention to purchase counterfeit fashion accessories. De Matos et al., (2007) indicated that perceived risk, previous purchasing experience, subjective norm, integrity, and price-quality inference significantly influence attitude toward counterfeit accessories, while Kim and Karpova (2010) indicated that product appearance, previous purchasing behavior, value consciousness, and normative susceptibility are significant predictors of attitude toward buying counterfeit fashion accessories. Regarding purchase intention, Kim et al., (2009) found moral judgment to have a significant, negative influence, while Koklic (2011) found

attitude, moral intensity, and perceived risk to significantly affect consumers' intention to purchase counterfeit accessories. Additionally, scholars have examined consumers' attitudes and purchase intentions toward counterfeit accessories and the relationship between such constructs. De Matos et al., (2007) identified that consumer intentions to purchase counterfeit accessories are dependent on the attitudes they have toward counterfeits, while Koklic (2011) confirmed that unfavorable attitudes toward purchasing counterfeit products negatively affects consumers' intentions to purchase such products.

Also apparent in previous studies, scholars have suggested various strategies that could be utilized to deter the demand for counterfeit fashion accessories. A major shift is seen in many researchers suggesting provision of consumers with anti-counterfeit education, which communicates the negative aspects of counterfeit product consumption (Ha and Lennon, 2006). While anti-counterfeit educational strategies have consistently been mentioned by scholars, previous research has only suggested the implementation of anti-counterfeit educational campaigns to deter demand, and the effectiveness of such initiatives have not been tested. Therefore, building on literature that currently exists on this topic, the effectiveness of implementing anti-counterfeit educational campaigns to deter the demand of fashion counterfeit goods will be examined within this study.

As indicated by previous studies, many purchasers of counterfeit fashion accessories do not think they are doing anything wrong, nor are purchasers aware of the connection between the sale of counterfeit fashion accessories and illicit acts of crime, such as terrorism (Ha and Lennon, 2006; Marcketti and Parsons, 2006; Norum and Cuno, 2011). Additionally, prior purchasers of counterfeit fashion accessories indicated that purchasing a counterfeit product was just as good as purchasing the genuine brand, and therefore, they believed they were not hurting the economy (Norum and Cuno, 2011). As such, Norum and Cuno (2011) suggested that changes in attitudes toward counterfeit fashion accessories might be necessary to discourage demand. As a means to alter consumer attitudes toward counterfeit fashion accessories, Norum and Cuno (2011) recommended employing consumer educational programming, with a direct focus on the negative impacts that counterfeit production and consumption have on the economy and society.

While existing literature suggests several educational techniques to dissuade consumer demand for counterfeit fashion accessories, there have not been any empirical studies conducted to evaluate if the suggested educational techniques significantly impact consumers' perceived knowledge, attitudes, and purchase intentions. Studies have specifically advocated for consumer anti-counterfeit education, such as educational campaigns in airports (Kim and Karpova, 2010) and public service announcements (Ha and Lennon, 2006); however, there has not yet been a study that has developed and assessed the effectiveness of an anti-counterfeit educational unit. As such, the purpose of this research study is to provide an empirical analysis that examines the impact of anticounterfeiting education on consumers' perceived knowledge, attitudes, and purchase intentions of fashion counterfeit goods.

O'Cass and Frost (2002) reflect that fashion is the one factor that dictates the human psyche in presentday popular culture. While fashion is intended to be worn in a public environment, some individuals dress as a form of self-expression, while others dress as a way to conform to societal norms. Consumers want branded and authentic fashion products because such does or may evoke feelings of exclusivity in society.

Consumers look at media such as fashion magazines, and wish to adorn themselves in the same designer items (Juggessur, 2011). Ledbury Research (2007) generated insight about how consumption of fashion or fashion accessories reflects changes in consumer behaviors and attitudes, higher incomes, and ready access to credit systems. Because consumers want luxurious, fashionable accessories with popular brands in their wardrobes, they are motivated to consume counterfeit accessories in compensation for limited budgets (Kim and Karpova, 2010). This behavior, or conspicuous consumption within a society of wealth, is well recognized and 
documented (Veblen 1899). O'Cass and Frost (2002) also argued that such conspicuous consumption is undertaken or pursued in order to enhance one's position in society, which can be achieved through signaling wealth, public demonstration and communicating affluence to others.

Scholars have suggested that consumer awareness of the phenomenon of counterfeiting fashion accessories is crucial to a positive change in attitude and behavior regarding the purchasing of counterfeit merchandise (Berman, 2008; Cordell et al., 1996 ;)

Grossman and Shapiro (1988) noted that, counterfeiting of fashion accessories arises in markets with imperfectly informed consumers. However, educational programming that provides relevant facts regarding the negative outcomes of purchasing counterfeit apparel accessories is argued to influence consumer buying intentions (Marcketti and Shelley, 2009).

Creating consumer awareness that highlights the advantages of buying authentic fashion accessories and the damaging social effects of supporting counterfeit production is essential to this situation (Ang et al., 2001; Kim and Karpova, 2010; Nia and Zaichkowsky, 2000; Wilcox et al., 2009). Also, it is argued that consumer education can allow consumers to identify counterfeits, deter them from this illegally-produced merchandise, and make ethical, honest purchase decisions (Berman, 2008; Cheek and Easterling, 2008; Juggessur, 2011). Furthermore, Romani et al., (2012) argued that by providing information on counterfeiting to consumers: it helps battle counterfeiting in general and it also aids to heighten the consumer's willingness to purchase (WTP) authentic merchandise.

However this is not the case in Ghana, hence this research focuses on consumer/customer education to gain insight into its effect on consumer knowledge, attitudes, and planned behaviors toward purchasing counterfeit fashion products within Ghana. Cordell et al. (1996) suggest that consumers' perceptions of counterfeiting of fashion accessories might be modified if education is provided. Thus the researcher seeks to put a serious dent on this fashion accessories counterfeiting through educating consumers who think this counterfeiting of fashion accessories is a trivial novelty, through the development of a consumer education program and determining its efficacy.

\subsection{Objectives}

The study determined the following:

1. To examine the effectiveness of anti-counterfeit education in changing consumers' perceived knowledge toward fashion counterfeit goods.

2. To evaluate the effectiveness of anti-counterfeit education in changing consumers' attitudes toward fashion counterfeit goods.

3. To ascertain the effectiveness of anti-counterfeit education in changing consumers' purchase intentions toward fashion counterfeit goods.

\section{Literature Review}

\subsection{Practical Background}

Intangible assets, such as goodwill and intellectual property, constitute a significant share of many firms' equity. They are often the result of extensive investments in research and development, careful brand management, and a consistent pledge to high quality, reliability, and exclusiveness. However, the growing momentum of emerging markets in Asia, where these intangible assets are difficult to protect plus a general trend in favor of dismantling border controls to ease the flow of international trade, and the increasing integration and interaction between organizations in disparate locations, require new measures to protect these assets and safeguard companies from unfair competition. Product counterfeiting in particular which is the unauthorized manufacturing of articles which mimic certain characteristics of genuine goods and which may pass themselves off as registered products of licit firms has developed into a severe threat to licit firms and consumers alike (Organization for Economic Cooperation and Development, 1998).

The implications for manufacturers and brand owners are multifaceted. On the one hand, firms are likely to face a loss of revenue owing to substitution effects by illicit goods and constraints on product pricing (Montoro-Pons and Cuadrado-Garcia, 2006). Substandard imitation products that are difficult to distinguish from genuine goods can diminish the level of quality associated with a product or firm. Moreover, large numbers of low-cost counterfeits can reduce the perceived exclusiveness of fashion products (Wilke and Zaichkowsky, 1999). On the other hand, firms may experience increased brand awareness as well as additional demand due to bandwagon and network effects (Nia and Zaichkowsky, 2000; Barnett, 2005; Yao, 2005). Counterfeit production can foster learning effects among illicit firms (Die Zeit, 2006), but a high market share of counterfeit apparel, may at the same time establish lock-in effects and barriers to entry for emerging legitimate competitors (Kirkpatrick, 2007). 
However, in most cases the negative implications outweigh the positive effects by far: preventive measures to ensure a high level of quality despite the existence of counterfeit articles, considerable enforcement costs in cases of counterfeit occurrence, expensive product recalls, potential liability claims in cases of health and safety hazards for consumers, customer confusion and brand dilution are in fact of major concern (Feinberg and Rousslang, 1990; Liebowitz, 2005). A firms' efforts are often undermined by lax enforcement policies in countries that are notorious for their vivid counterfeit production particularly China (Hung, 2003) and, in some markets, by consumers who actively engage in buying counterfeit goods (Moores and Chang, 2006; De Matos et al., 2007).

Because the counterfeiting of fashion accessories is an international phenomenon, many scholars have written about various aspects of the topic. According to the International Anti-Counterfeiting Coalition (IACC), counterfeiting of fashion accessories is a threat to global health and safety, as many counterfeit operations have poor working conditions, do not pay their employees fair wages or benefits, and often use forced child labor. In addition, the IACC acknowledged profits from counterfeiting have been linked to funding organized crime, drug trafficking, and terrorist activity.

Also counterfeiting is defined as a reproduction that appears identical to a legitimate product in appearance, packaging, trademarks, and labeling (Ang et al., 2001). Within the counterfeiting industry, there are multiple forms of product counterfeiting that may occur (Kim and Karpova, 2010; Koklic, 2011). Furthermore, Koklic (2011), posits that a major form of counterfeiting is the deceptive counterfeiting, in which consumers believe they have purchased a legitimate good, when in fact the product is actually fake. Also, Grossman and Shapiro, (1988), identify another form as non-deceptive counterfeiting, where consumers are fully aware of purchasing a counterfeit, and intentionally seek out and purchase such illegitimate or fake goods.

To address the purpose of this study, whether consumer education affects consumers' future purchase intentions, literature was explored in these areas: consumers and their behavior, consumer perceptions, and consumer education. The foundation of literature led to a theoretical framework that is presented in this chapter.

\subsection{History and Theory of Counterfeiting}

Counterfeiting is the production and sale of fake products in the marketplace. Counterfeits possess a registered trademark or name, and are often produced to take advantage of the benefits generated by the original, branded products (Bian and Veloutsou, 2007).

Technological advancements and globalization have substantially contributed to the growth of the counterfeiting problem (Wang and Song, 2013). This phenomenon dramatically developed beginning in the 1970 's and has become a major concern for governments and businesses (Bian and Veloutsou, 2007). Counterfeiting poses a threat to the welfare of consumers and negatively impacts innovation. Gentry et al., (2006) posits that varied factors tends to drive counterfeiting of fashion accessories; on the supply side, it is driven by institutional factors, such as the likelihood of detection and the penalties imposed in a market, however on the demand side, consumer behavior is the main motive. Consumers may buy counterfeit fashion accessories as status symbols to be categorized as a prestigious social group in which they would like to belong. When a person wears a counterfeit fashion accessory, they are choosing to identify with the people wearing the original fashion product and are claiming to belong to the same social class as the original luxury brand users (Wilcox et al., 2009).

Furthermore, price has been cited as the most influential reason as to why consumer demand for counterfeit products has increased in recent years (Gentry et al., 2006). A counterfeit fashion accessories price is a fraction of the genuine product's price, and it is suggested by Carpenter and Lear, (2011), that consumers buy these counterfeit fashion products to avoid the increased cost of buying an original. Even though counterfeit fashion products are often lower in terms of quality, they offer other utilities which are associated with consumers of original brands such as personal status (Wilcox et al., 2009).

\subsection{Types of Counterfeit Merchandise}

Four different characterizations of counterfeit products is suggested by Berman (2008).

In the first category, consumers knowingly buy products that are counterfeit, because the product is much cheaper in comparison to the authentic article; it is purchased from a different channel of distribution, and may not be packaged exactly like the authentic item.

In the second category, consumers are deceived by the counterfeit product and think that the product is authentic because it is so well engineered. In this category, counterfeiters analyze a product piece-by-piece, and recreate the counterfeit item exactly as the original is made.

In the third category, consumers purchase counterfeit items produced by an actual manufacturing factory that also produces the original product. Outsourced manufacturers hire another shift of employees to work during the hours that the factory is closed, and use the same machinery to recreate counterfeits of the 
original, authentic merchandise.

In the fourth category, consumers purchase products produced by the original manufacturer, but with manufacturing defects revealed through a quality assurance process. This merchandise is intended to be sold as lower quality merchandise, or destroyed, but many times it is unknowingly (to the manufacturer) taken from the factory and sold as high-quality, first rate merchandise to other suppliers (Berman, 2008).

Due to an inability on the part of many consumers to afford authentic fashion accessories at the high price-point in which it is sold, such consumers resort to the purchase of counterfeit versions of the same fashion merchandise they aspire to own (Han et al., 2010). These counterfeits, which typically sell for a lesser price, allow consumers to experience a brand, even though the product is inauthentic and of lesser financial value (Gentry et al., 2001). Although consumers may be aware that the production of counterfeits is unlawful, these consumers may not view their purchases as dishonest or irresponsible (Kim and Karpova, 2010).

Differences in consumer attitude towards sharing may be directly related to the philosophy of sharing. The mass consumption of counterfeits in Ghana presents an opportunity for all designs and products to be shared by society (Ang et al., 2001). However, some consumers may wish to purchase these counterfeit products because of a high rate of fashion change. It may be worth it to some consumers to purchase a lesser-priced, counterfeit product, which can be replaced when new fashion designs and products emerge during the next fashion season. In fact, some consumers may even prefer counterfeit fashion accessories more than authentic merchandise, because of this reason (Juggessur and Cohen, 2009).

\subsection{Consumers and Why They Buy Counterfeit Fashion Accessories}

In order to first understand the process of counterfeit fashion accessories consumption, the types of consumers who purchase luxury fashion accessories must be identified. Clark et al., (2007) suggested the existence of two types of consumers who purchase luxury fashion accessories; status seeking consumers and role-relaxed consumers. According to Clark et al., (2007), status-seeking consumers are concerned with what the group they wish to identify with considers prestigious. In other words, status-seeking consumers wish to attain fashion products that will increase their status in society. Clark et al. (2007), further states that role-relaxed consumers choose a product because of the characteristics of that specific product. In other words, role relaxed consumers are more concerned with how the characteristics of a product will enhance their lives, regardless of social status.

Too many consumers, gaining status in society is one of the most important factors in the decision to purchase a fashion item. These consumers wish to embellish their consumption by purchasing items that will be seen, and are associated with wealth (Chao, 2006). It is further argued by Chao, (2006), that this is the main reason behind status-seeking individuals furnish the rooms in their homes that will be seen by others with more decadent furnishings than those rooms that are kept closed during social gatherings. These demonstrations of wealth are used because they are important social symbols, which help individuals rise in hierarchy on the social status ladder. Such individuals wish to own products that symbolize a prestigious image and status position (O'Cass and Frost, 2002). These products must demonstrate brand prominence, which Han et al., (2010) describes as the extent to which a product has visible markings that help ensure observers recognize the brand. Brands with social meaning allow consumers to cast images of wealth or gain societal approval (Juggessur, 2011).

According to Chao and Schor (1998), consumers fear that other members of society will not see their desired social position, and therefore, consumers are more concerned with purchasing fashion products that will be socially visible. These status seekers may spend money to signal their success, and by implication, their own competencies. Chao and Schor (1998), therefore suggested that socially visible goods are associated with social standing.

\subsection{Attitudes and Behaviors towards Counterfeit Fashion Accessories}

According to Huang et al., (2004), attitude is a learned predisposition to behave in a consistently favorable or unfavorable way with respect to a given object. It is the way one thinks, feels, and acts toward some aspect of their environment. Attitudes serve important social functions such as self-expression and self-presentation. Wilcox et al., (2009) found that the demand for counterfeit fashion products continues to grow because of the value-expressive functions that the genuine brand delivers. A case in point is the purchasing of a Gucci counterfeit by an individual because the brand reflects their personality.

Kim and Karpova, (2010), posited that consumer motivations and consumers' attitudes towards purchasing counterfeit fashion goods is highly influenced by such factors as product appearance, past purchase behavior, and value consciousness.

Phau and Teah (2009) explored how social and personality factors influences consumers' attitudes towards counterfeits of fashion products and how it further influences purchase intention. They analyzed the effect of normative and information susceptibility, collectivism, value consciousness, integrity, and status consumption on 
the attitudes and purchase intentions of consumers towards counterfeits of fashion products. Their results indicated that information and normative susceptibility goes a long way to affect the attitude of an individual towards the purchasing of counterfeit fashion accessories. Phau and Teah (2009), further posited that value consciousness and status consumption had a high level of influence purchase intention.

Also, Hidayat and Diwasasri, (2013) whiles examining the influence of antecedents of attitudes towards counterfeiting fashion products consumers and its relationship to purchase intentions of counterfeit product argued that social and personality factors significantly impact attitudes. It was further argued by same that positive attitudes towards counterfeit products strengthen purchase intentions, regardless of socio-economic status.

\subsection{Counterfeiting as an Attractive Business Format}

Because of an increase in counterfeit fashion accessories production and distribution, there is already a strong market demand for counterfeit fashion accessories. Counterfeiting is an attractive business venture because there are no overhead costs, a low possibility of prosecution, and a high percentage of profitability (Delener, 2008). Because counterfeiters do not have operating costs such as marketing efforts, promotions, and research and development of products, counterfeit manufacturers enjoy status as an unjust competitor within trade markets (Berman, 2008). While firms continue to fight against counterfeiting, Ang et al., (2001) note that counterfeiters will find ways to integrate their businesses into the economy as long as demand for counterfeit fashion products remains vigorous. According to Ledbury Research (2007), as long as a demand for fashion accessories continues to increase, then the production of counterfeits of such fashion accessories will also increase. Ledbury Research (2007) further posited that it is very much possible for the same amount in monetary terms of counterfeited and authentic fashion accessories, to be purchased from famous brands. In addition, it is argued that many firms have internationally outsourced the manufacturing of their products geared towards increased profit margins, and hence developing countries are benefiting from the manufacturing prospects of producing inauthentic fashion accessories (Gentry, et al., 2001).

\subsection{Distribution of Counterfeit Fashion Accessories}

The distribution of counterfeit fashion accessories has clearly permeated the consumer market on a large scale, and with a multitude of channels to reach those consumers. However, there is not a way to accurately measure the problem, because of the volume of imported, counterfeit items that are never seized by the agencies (McIntyre, 2011).

The art of counterfeiting is most profound in Asia especially China. Most global manufacturing plants in these parts are skilled in creating counterfeit fashion accessories that are nearly identical to the authentic product. These firms are difficult to close down because many of them are established through state interventions, who often overlook copyright laws and intellectual property rights (Betts, 2004; Phillips, 2005). Furthermore, most state cultures consider this production as a means of living, and the uses counterfeit production as an opportunity to generate large amounts of income (Phillips, 2005).

Chaundry and Walsh, (1996), argued that many factors thwart the ability to implement laws that restrain counterfeit fashion accessories from been transported across borders or been traded in within such borders. Many licensed products are often sold, and redistributed, through subcontracted manufacturers. With the usage of illegal dealership systems, counterfeiters mix authentic fashion accessories with counterfeit merchandise, and both types are sold together (Hung, 2003).

Counterfeiting fashion accessory firm have developed savvy strategies to distribute their products globally; such as the sewing of counterfeit fashionable handbags inside of the linings of generic handbags to disguise the shipment of their products (Lambkin and Tyndall, 2009). Also, Lambkin and Tyndall, (2009) further states that counterfeiters use separate shipment methods for different components of their inauthentic fashion merchandise. The parts are shipped separately, and then assembled in the country of end sale, thereby allows counterfeiting firms to reduce the likelihood of having their merchandise confiscated by the destination country's government (Lambkin and Tyndall, 2009). The Anti-Counterfeiting Group also reports that counterfeiting firms use large trading centers in countries such as Paraguay and the United Arab Emirates, because their shipments are often unchecked.

The Organization for Economic Co-Operation and Development (2007) cites free trade zones as areas for investigation regarding counterfeit merchandise sales. Free trade zones are areas where international traders can store, assemble and manufacture products that are moving across borders with minimal regulation. However, such free trade zones abuse the statutes setting them up and tend to allow counterfeiters to alter the initial country of origin and repackage their products with counterfeit trademark symbols (Organization for Economic Co-Operation and Development, 2007). 


\subsection{Industry Efforts and Controls at Counterfeiting of Fashion Accessories}

Counterfeiting of fashion accessories has grown exponentially year-to-year into a global problem, and puts economies across the world at risk (Betts, 2004). The Organization for Economic Co-Operation and Development (2007) advocates for serious action to be taken by governments, organizations, and consumers. The organization for Economic Co-Operation and Development emphasizes the need for public support in the consumer market, as well as stronger relationships between industry competitors and government. Because of this need for consumer education, many firms are taking a stand against counterfeit manufacturers and spending millions of dollars annually by hiring legal consultants and private investigators to combat the problem through awareness and legal action (Betts, 2004; Chao, 2006).

Because of the impact that counterfeiting has on international trade, it is important for firms to address the problem directly. The use of marketing communications in an effort to educate consumers on counterfeiting is imperative to strengthening a brand's reputation (Romani et al., 2012). Firms are urged to be concerned with the copying of their products when that product has been counterfeited before (Berman, 2008). Though most firms do not make the effort to combat the problem of counterfeiters as they would a regulated competitor, however these counterfeiters are some of the biggest competitors in the industry (Phillips, 2005). Furthermore, it is critical for firms to take necessary precautions that will ensure brand loyalty and customer retention through a strong brand image (Lambkin and Tyndall, 2009). A major way of doing this is through ensuring an informed consumer base through regular education and that is exemplified by famous fashion brands, creating campaigns geared towards the firm educating consumers on how to differentiate between an authentic piece of fashion accessories and a counterfeit one (Gistri et al., 2009).

With due recognition of the effects of counterfeiting of fashion accessories on operational and financial performance of firms, such firms tend to put in place strong legal teams as well as investigators to fight counterfeit reproduction of its commonly counterfeited fashion accessories (Betts, 2004). The employing of such legal teams by fashion houses according to Phillips, (2005) is geared towards ensuring that their brands or products remains an exclusive item. Without these efforts Phillips, (2005) claims that the demand for these counterfeit fashion accessories or products would drive the illegal trade market.

Furthermore, some of these fashion accessories, are made from the finest and rarest materials, cost very much and only few are produced or circulated; however, the wait list for them causes consumers to resort to the purchase of high-quality counterfeit versions. Thus, through striving to keep exclusivity and authenticity intact firms tend to fight its counterfeiting (Phillips, 2005).

Also, fashion houses that produce popular brand fashion accessories, in a bid to keep customers educated on the risks involved in purchasing counterfeited fashion accessories, are gradually tilting towards the creation of pages on their websites to educate consumers about counterfeiting. Not only does these undertakings demonstrate concern for their own firm, it goes a long way to communicate to consumers that increases in counterfeit production create lost revenues, including sales taxes, that could be used for new hospitals, schools, and the hiring of police officers and firefighters to protect the public (Philips, 2005). In turn, this lost revenue causes firms to enforce cutbacks in their workforces. Manufacturers of inauthentic fashion accessories do not pay taxes, and may treat their employees unfairly, often using child labor as a means to create counterfeit fashion products. Counterfeiting of fashion accessories creates labor inequities, smaller revenues for intellectual property owners, and ultimately destroys the character and image of a fashion brand.

\subsection{Anti-Counterfeiting Outcomes and Proposed Reasons}

The negative impacts caused by counterfeit practices have drawn a great deal of attention from multinational organizations, national governments, legitimate manufacturers and brand holders (Green and Smith, 2002). In response to the fast expanding counterfeiting phenomenon, national anti-counterfeiting legislations have been strengthened ( e.g., US Trade Mark Counterfeiting Act 1984, UK The IPR 2002 ACT), international legal anticounterfeiting measures have been developed (e. g., the General Agreement on Tariffs and Trade, Trade-Related Intellectual Property Rights), various global anti-counterfeiting organizations (e. g. the International Anticounterfeit Coalition, Anti-counterfeiting Group) have been set up with the same purpose; to eliminate counterfeiting. Moreover, individual firms have been dedicated themselves to curb counterfeiting.

Despite the increased efforts of national governments and organizations, the loss figure caused by counterfeiting continues to climb. The value of counterfeit goods in the world market is believed to have grown by $1100 \%$ since 1984 ; within seven years the estimated value of counterfeit products increased by $\$ 140$ billion (Chaudhry and Walsh 1996; Freedman, 1999). Furthermore, the figure for counterfeited merchandise reached $£ 10$ billion in 2003 in the UK alone, which is almost 3 times more than in 2001 (ACG 2004), and the International Chamber of Commerce (ICC) projected that the counterfeit market would soon exceed $\$ 500$ billion per year (ICC 2003). Clearly, the reality is business as usual for most counterfeiters (Gentry et al. 2006). Overall, the success of governments has been limited (Olsen and Granzin 1992).

Several factors have contributed to the growth of this phenomenon. Apart from the obvious financial incentive 
(Ang et al., 2001), the increase may stem from decentralization of political power in many regions, as regions become more concerned about the immediate welfare of local firms, employees of those firms and other regional stakeholders. This is especially true in transitional economies such as China, Vietnam and Russia (Shultz II and Ardrey 1995). Harvey, (1988) and Roberts, (1985), states that counterfeiting is regarded as an industrial development strategy for some developing countries. According to Harvey, (1988), some producers in developing countries have not mastered the ability to develop products of their own, however, they have progressed enough to produce replica products. Since they have not gained a reputation that would help their products to stand on their own, it is more likely that they adopt a counterfeiting strategy.

At a more basic level, some countries and many counterfeiters refuse to accept the ideas and concepts espoused by the WTO and pressure from developed countries; indeed, they may even acknowledge that they engage in or support counterfeiting (Chow 2000). Bush et al., (1989), claim that counterfeiting continues to flourish because multinational marketing has created high worldwide demand for well-known brands. In addition, technological advances enable counterfeiters to produce brand name products easily (Gentry et al., 2001; Delener 2000) and the removal of trade barriers makes it likely that counterfeiting will continue to abound (Cottman, 1992). Inadequate penalties for commerce in counterfeiting and weak enforcement of the respective laws and regulations are also blamed for the growth in counterfeit trade (Kay, 1990). Irrespective of these issues which are considered responsible for the wide spread of counterfeiting, a number of researchers claim that counterfeit will always exist and grow so long as the demand for them is still strong (Chakraborty et al., 1996). This statement is in the same vein as the economic theory which suggests that if there is little or no demand for a product, supply will also decrease.

It would be naive to claim that the demand for counterfeit products should take full responsibility for the boom in counterfeiting, but it is certainly one of the main reasons why anti-counterfeiting campaigns appear to achieve little success despite the efforts by countries to improve and enforce relevant legislation (Bamossy and Scammon, 1985). It is argued that an understanding of why consumers are accomplices to counterfeiting, before victims of counterfeiting can make any successful achievements in curbing the practice.

\subsection{Impact of Education on Counterfeiting of Fashion accessories}

As the severity of the counterfeiting problem rises, it has been suggested that consumer education and awareness could lessen the impact of counterfeit manufacturing (Juggessur, 2011; Marcketti and Shelley, 2009). Romani et al., (2012) noted that there are two major benefits for educating consumers on the effects of counterfeiting; it increases consumers' willingness to purchase authentic fashion accessories and it helps combat counterfeiting in general.

Kozar and Marcketti (2008) argued that consumers who are more educated on issues of fashion accessories counterfeiting and its negative repercussions are more likely to identify the production, selling, and buying of counterfeit merchandise as an illegal act. Furthermore, consumers who view counterfeiting as illegal are less likely to knowingly buy counterfeit merchandise. Kozar and Marcketti (2008) noted that family and consumer Science courses provide an exceptional opportunity to educate consumers on ethical issues such as the subject of counterfeit fashion accessories consumption. To strengthen the need for consumer education, Kozar and Marcketti (2008) stated, that education has a significant impact on ethical decision making.

Marcketti and Shelley (2009) supported the argument that education on the adverse impacts of counterfeiting, may change their future purchase intentions. This is due to the believe that consumers been uneducated on the subject of counterfeiting is a main driving force behind continuous consumption of such counterfeited fashion accessories, hence with substantial knowledge of the subject will come a greater desire to purchase the genuine products. In terms of improving the fashion accessories counterfeit pandemic, Marcketti and Shelley (2009) stated that educational programming that provides relevant facts regarding the negative outcomes of purchasing counterfeit apparel goods may influence consumer buying intentions.

Furthermore, Ha and Lennon, (2006), indicated that most consumers are unaware of the link between terrorism and counterfeit product sales. As a means to better inform consumers about the negative aspects of counterfeiting, Ha and Lennon, (2006), suggested implementing educational and public policies that emphasize the risks of counterfeiting. Kim et al., (2009), suggested a need for to consider developing advertising campaigns that highlight how the consumption of illicit fashion products imposes harm on individuals and society. Kim and Karpova (2010) suggested educating consumers by implementing anti-counterfeiting campaigns which stress the link between fashion counterfeits and negative social phenomena such as sweatshops, loss of legitimate manufacturing jobs and unpaid taxes.

Similarly, Kozar and Marcketti (2011) suggested that educators should discuss the negative results of distributing and purchasing counterfeit goods as a technique to encourage socially responsible purchasing behavior. Kim and Karpova (2010) also implied that if educators developed special anti-counterfeiting units as part of a curriculum that addresses social responsibility, consumers might better understand the fashion 
counterfeiting phenomenon and its damaging consequences. Norum and Cuno (2011) suggested that educators might be able to deter the purchase of counterfeit goods by educating consumers about the dangers associated with counterfeiting. Also, Norum and Cuno, (2011), argued that such education should be directed at areas including; instilling fear of punishment; recognizing the negative impacts that counterfeits have on jobs, loss of tax revenues, balance of payments, and crime; and the use of profit from counterfeit sales toward the funding of organized crime and illicit activities.

Also, in favor of anti-counterfeit education, Phau et al. (2009) indicated that consumers are often illinformed about the detriments of counterfeit trade. As a means to spark change, Phau et al. suggested more cohesive efforts to educate consumers about the negative effects of their buying behaviors on the economy. While these educational programs may be conducted within specific settings, Ha and Lennon, (2006), argues that other potential audiences may include employees of multinational firms, tourism related, and other domestic businesses. Also, Ha and Lennon, (2006); Kim et al., (2009) have indicated that anti-counterfeit education has the potential to alter consumers' viewpoint toward fashion counterfeit goods.

Ha and Lennon, (2006), suggested that education might have the capability to change consumers' views on purchasing fashion counterfeit goods if the negative aspects of counterfeit product consumption, such as how it affects the economy, society, and consumers, are addressed. Likewise, Koklic, (2011), suggested that the implementation of consumer education has the potential to influence consumer attitudes and purchasing intentions towards fashion counterfeit goods. Koklic, (2011), indicated that the perception of consequences for oneself (perceived risk) and perception of consequences for others (moral intensity) could serve as two powerful areas that might prove effective in changing an individual's attitudes and intentions.

\section{Design /Methodology/Approach}

A descriptive and exploratory research design was adopted to enable the researcher to find out and understand issues relating to counterfeiting within the fashion industry and what advantages will be arrived at from education of consumers on the effects of the illicit trade on individuals, society and the national economy as a whole.

The target population of this study consist of sellers of fashion accessories and purchasers of fashion accessories, within Greater Accra Region of Ghana.

The researcher interviewed hundred (100) individuals from varied areas of the fashion sector for this study whereas the sample frame consist of sellers of fashion accessories and purchasers of fashion accessories, within the Osu and Accra Central Business District ends of the fashion market in Ghana.

In line with the purpose of this study, both primary and secondary sources of data were used. The collection of primary data became obvious since there was the need to gather the views of different respondents within the fashion accessories market set-up who had different set of skills, attitude and behavior, all driving towards the goal of massive realization of setting up a high-end fashion industry in Ghana.

In this research, the statistical Technique is used and the frequency count method was adopted. Data collected was coded and analyzed systematically using frequency table, percentages, mean and standard deviation. Creswell (2009), stated that interviews should be transcribed and collated with the information from the field. Interview data was recorded and whiles other parts handwritten in a notebook. Codes were developed according to the questions posed in the interview.

Results are presented in pie chart forms with a brief description of the main features using the Statistical Packages for the Social Sciences (SPSS). The interpretation of results is also carried out under this chapter. 


\section{Result / Findings}

Figure 3.1: Gender of Respondents

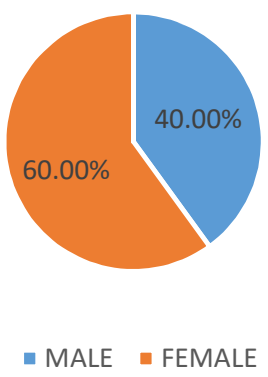

Figure 3.1 depicts the gender of the various respondents. A total of Sixty (60) respondents representing $60 \%$ were Females whiles Forty (40) respondents representing 40\% were Males. This goes to suggest a high level of participation in the fashion accessories business by women or females.

Figure 3.2 Ages of Respondents

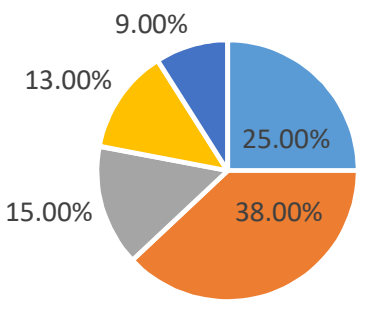

$=20-30=31-40=41-50 \quad=51-60 \quad$ - $61-70$

Figure 3.2 depicts the ages of the respondents. Whiles Twenty-Five (25) of the respondents representing $25 \%$ were within the ages of 20-30 years, another Thirty-Eight (38) respondents representing 38\% of respondents were within the ages of 31-40 years. The ages between 41-50 years had Fifteen (15) respondents representing $15 \%$ of total respondents. Furthermore, Thirteen (13) respondents representing 13\% was derived for 51-60 years, whiles Nine (09) respondent representing $9 \%$ was within the ages of $61-70$ years.

\section{Figure 3.3: Respondent's Level of Education}

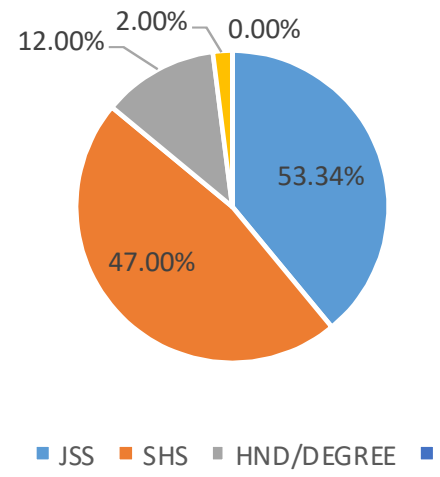

Figure 3.3 depicts the level of education of the various respondents. Whiles Thirty-Nine (39) of the respondents representing $39 \%$ of the total respondents were holders of JHS certificates, Forty-Seven (47) of them representing $47 \%$ of total the respondents were SHS certificate holders. Furthermore, Twelve (12) of them, representing $12 \%$ of total respondents were HND/ Bachelors' degree holders, whiles another Two (02) 
respondent representing $2 \%$ holds a Master's degree.

Figure 3.4: Respondent's Number of Years Worked

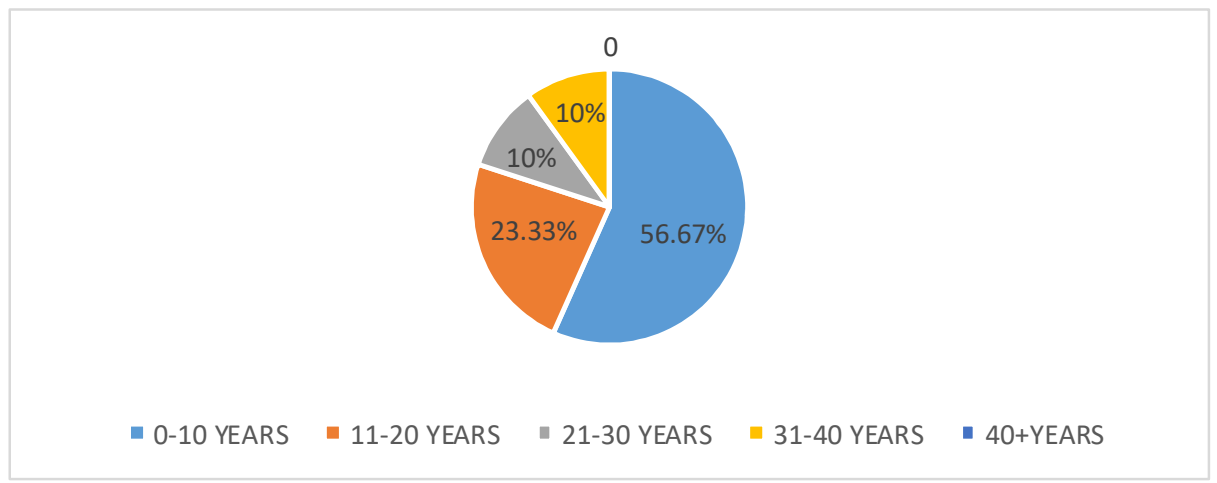

Figure 3.4 shows the various responses collated for the number of years the respondents have worked within the fashion accessories business. Seventeen (17) respondents representing $17 \%$ of the total respondents had worked between 0-10 years within the fashion accessories industry; Forty-Three (43) of them representing 43\% of the total respondents had worked between 11-20 years within the fashion accessories industry; whiles Twenty-Three (23) of the respondents representing $23 \%$ of total respondents have worked between 21-30years and another Ten (03) responses representing another $10 \%$ of respondents have worked for 31-40years.

Figure 3.5: Environmental impact from counterfeited fashion accessories

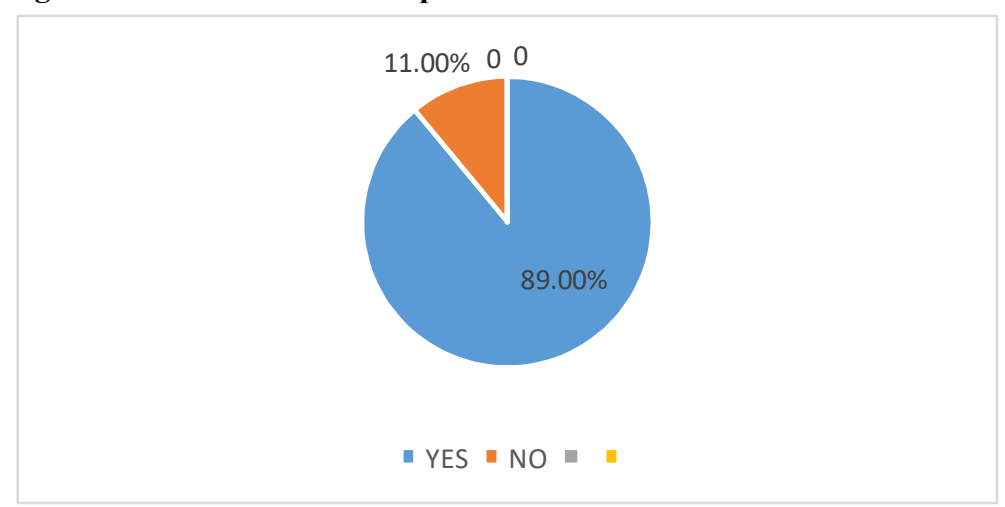

Majority of respondents indicated that there is an environmental impact of counterfeit fashion accessories with a whooping Eighty-Nine (89) responses representing 89\% of respondents answering "YES" whiles only Eleven (11) respondents representing $11 \%$ of total respondents answering "NO". This goes to suggest that the most consumers, be it traders or actual end users of fashion accessories experience serious adverse effects in terms of environmental impact due to the counterfeiting of fashion accessories. 
Figure 3.6: Types of Counterfeiting Effects

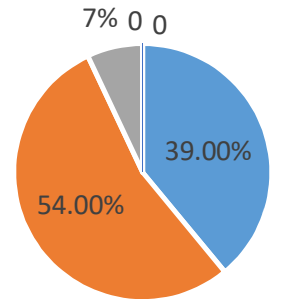

$$
\begin{aligned}
& \text { - STRONGLY AGREE } \text { - AGREE " NEUTRAL } \\
& \text { - STRONGLY DISAGREE — DISAGREE }
\end{aligned}
$$

Thirty-Nine (39) respondents representing $39 \%$ of total respondents supported the assertion that there are effects on the environment as well as social and economic impact of counterfeiting of fashion accessories. Furthermore, such effects are also admitted to by Fifty-Four (54) respondents representing 54\% of total responses answering "Agree". However, Seven (07) respondents representing 7\% of total responses answered "Neutral". No respondent "Disagree" or "Strongly Disagree". Respondents argued that on the economic front, issues such as lost profits and damage to brand reputation of fashion accessories as well as stalled innovation and fair economic opportunities across industries are encountered as a result of counterfeiting. Social and environmental wise, it leaves in its wake challenges of child labor and increased pollution.

Figure 3.7: Fashion Industry is sufficiently regulated and controlled

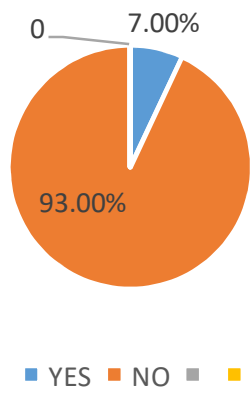

Most of the respondents in figure 3.7 believes that the country's fashion industry is not effectively regulated. This is evident by the $93 \%$ rate of returns from Ninety-Three (93) respondents who answered "NO" to the assertion. However, Seven (07) respondents representing 7\% answered "YES" to the assertion, thereby showing a belief of lack of enough regulations within the Fashion Industry.

Figure 3.8: Knowledge of laws or regulations relating to Counterfeiting of Fashion Accessories

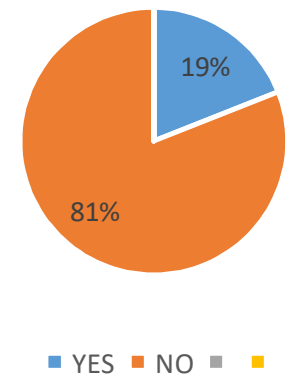

Figure 3.8 shows a weak knowledge by practitioners and dealers of fashion accessories about various laws and regulations which are meant to act as guards against counterfeiting. Whiles only Nineteen (19) respondents 
representing $19 \%$ of total respondents answered "YES" to the assertion that, they do have knowledge of laws relating to counterfeiting; Eighty-One (81) respondents however answered "NO" to the assertion of having knowledge of laws relating to the counterfeiting, thereby disagreeing with it.

Those that had knowledge about laws pertaining to counterfeiting which totaled Nineteen (19) and represented 19\% of total respondents mentioned the Trade Mark Act 664 of 2004, Trade Mark Act 876 of 2014 and the Criminal Offense Act 29 of 1960 . However, these respondents felt these laws are not deterring enough.

Figure 3.9: Compliance with Laws and Regulations

In relation to people conforming or complying with laws regarding counterfeiting of fashion accessories, eleven (11) of the respondents representing 11\% of responses answered "YES" thereby showing support for the assertion. However, Eighty-Nine (89) respondents do not believe and so answered "NO" to the statement and accounting for $89 \%$. This goes to show that the majority of the respondents believe that laws on counterfeiting of fashion accessories are not complied with.

Figure 3.10: Counterfeiting ought to be stopped

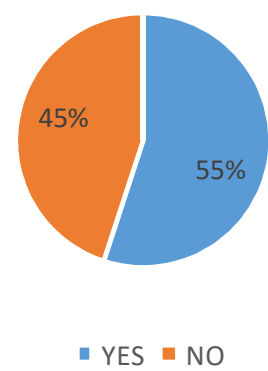

There was no clear cut agreement among the respondents as to whether illegal mining should be stop or not. Forty-Five (45) respondents which is $45 \%$ of the responses believe that there should be no ban on illegal mining by answering "NO" to the statement. However, another 55\% which is a total of 55 respondents answered "YES" to the statement hence showing support for the ban.

The majority of the individuals who answered "YES" stated so due to issues of damage to creativity, harmful to the consumer and profitability. In such counterfeited fashion accessories, one is bound to find traces of chemical coloring agents and paints harmful to consumer health. Furthermore, there is a huge impact of workforce within the Ghanaian fashion accessories industry. Hence, it is necessary to enforce controls for traceability and compulsory labelling.

\section{Figure 3.11: Best Source of Credible Information on Counterfeiting of fashion accessories within Ghana}

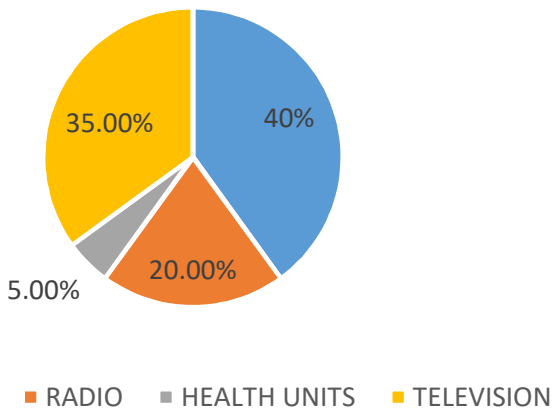

Figure3.11 depicts the response of the respondents regarding the best source of credible information on counterfeiting of fashion accessories in Ghana. Forty (40) respondents representing 40\% of total respondents answered "Internet"; another Twenty (20) of them also representing 20\% answered "Radio", whiles Five (05) respondents representing $5 \%$ of total responses answered "Health Units". However a further Thirty-Five (35) of the respondents representing 35\% think "Television" is a good source of information on counterfeiting activities. The media can be used to educate people about the adverse nature of counterfeiting through playing a monitoring 
and advocacy role geared towards informing the general public about the environmental as well as economic woes of counterfeiting. Also the media can stimulate industry ownership of sustained campaigns against counterfeiting by engaging with such industries and aiding to build capacity of stakeholders through creation of an understanding of the need to preserve the authenticity of fashion accessories industry as well as its resultant economic and environment impact for the collective good.

\section{Figure 3.12: Counterfeiting is Either Increasing or Decreasing in Ghana}

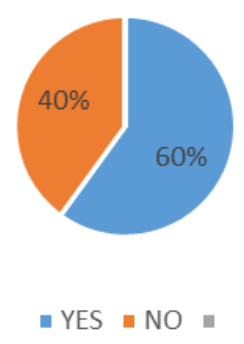

Sixty (60) respondents representing $60 \%$ of the respondents in figure 3.12 answered "No" to the assertion of Counterfeiting decreasing, however Forty (40) respondents representing 40\% of the responses answered "Yes". Which presupposes that Counterfeiting is not decreasing.

For those who answered "No" to the assertion of counterfeiting been on the decline, it is as result of lack of political will as well as the changing of tactics by the counterfeiters at varied times during the trade as well as their dynamic and innovative acumen.

\section{Figure 3.13: Most Branded Goods are Rip Offs.}

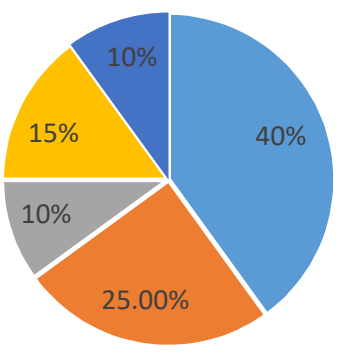

$$
\text { - STRONGLY AGREE — AGREE —STRONGLY DISAGREE }
$$

Forty (40) of the respondents representing $40 \%$ of total responses answered "Strongly Agree", furthermore to the assertion of most branded accessories been rip offs Twenty-Five (25) respondents also answered "Agree" representing $25 \%$ of responses. However, Fifteen (15) respondents, representing $15 \%$ of respondents stayed "Neutral"; Ten (10) respondents representing $10 \%$ of total responses answered "Strongly Disagree" to the assertion whiles another Ten (10) respondents representing $10 \%$ of responses answered "Disagree" to the assertion hence showing that the belief of most branded goods been rip offs thus fueling consumers purchasing of counterfeits. 
Figure 3.14: Likelihood of buying counterfeit if educated and knowledgeable in it

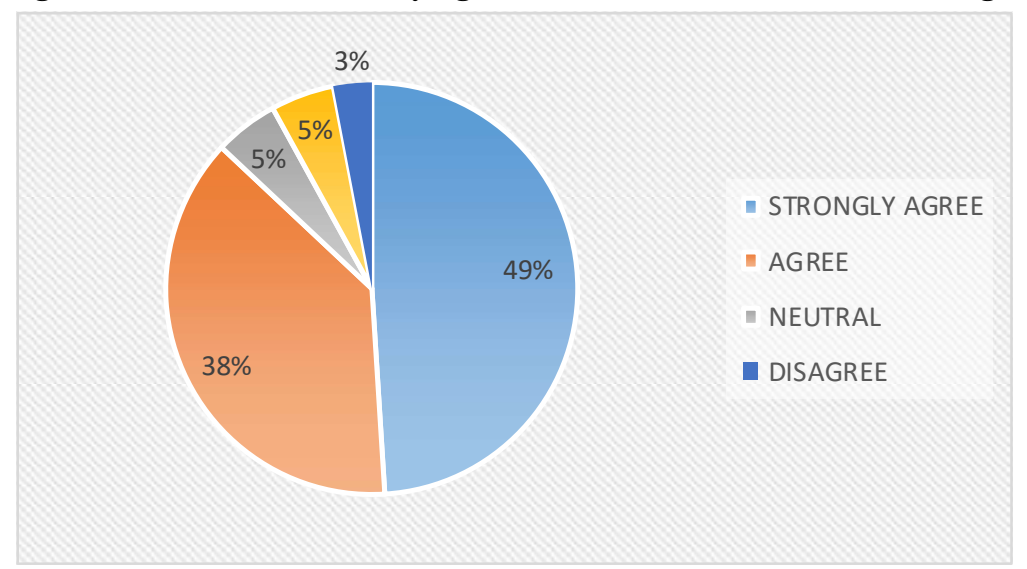

Figure 3.14 depicts the respondents' responses relative to the likelihood of buying counterfeit fashion accessories if they know about the product and the alternatives available to them. Whiles, Forty-Nine (49) respondents representing $49 \%$ of the total respondents answered "Strongly Agree" to the statement showing an indication that with education they are less likely to purchase or trade in counterfeit fashion accessories, Thirty-Eight (38) respondents representing $38 \%$ of total responses answered "Agree" to the statement, thus showing a strong response by respondents that with education on the impact and effects of counterfeit fashion accessories, consumers are likely to patronize it less. $5 \%$ of the total responses accounting for Five (05) respondents decided to stay "Neutral". However, Five (05) respondents representing 5\% of responses answered (Strongly Disagree" and Three (03) respondent also representing $3 \%$ of responses answered "Disagree"

\section{Figure 3.15: Willingness to pay for authentic Accessories}

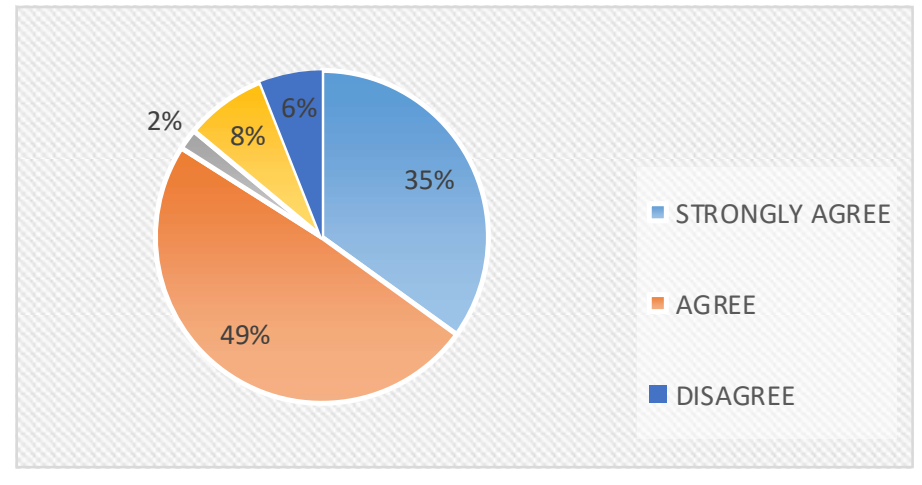

This chart depicts the responses of the respondents in relation to their willingness to part with a little excess for authentic fashion accessories. Thirty-Five (35) of the respondents representing 35\% of total responses answered "Strongly Agree", whiles Forty-Nine (49) of them representing 49\% of the responses answered "NO". This shows that regulations consumers are willing to get their money's worth by parting with a little bit more to acquire authentic accessories rather than paying less for counterfeited accessories. Furthermore, responses for "Neutral", "Strongly Disagree" and "Disagree" was received from Two (02) respondents representing 2\%, Eight (08) respondents representing $8 \%$ and $\operatorname{Six}(06)$ respondents representing $6 \%$ respectively. 
Figure 3.16: Linkage of Counterfeiting to Crime

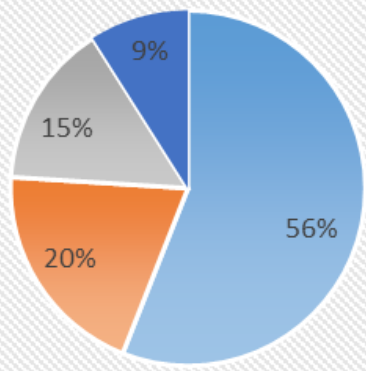

$=$ STRONGLY AGREE

- AGREE

- DISAGREE

Fifty-Six (56) of the respondents in figure 3.16 representing 56\% of total responses answered "Strongly Agree" to the assertion of counterfeiting been linked to crimes, furthermore Twenty (20) other respondents representing $20 \%$ of responses answered "Agree" to the assertion. For these individuals, counterfeiting is related to issues of crime such as terrorism, child labor, organized crime as well as sweatshops. Fifteen of respondents representing $15 \%$ of responses stayed "Neutral" and Nine (09) respondents representing $9 \%$ of total responses "Disagree" with the assertion.

\section{Figure 3.17: Relevance of Consumer Education}

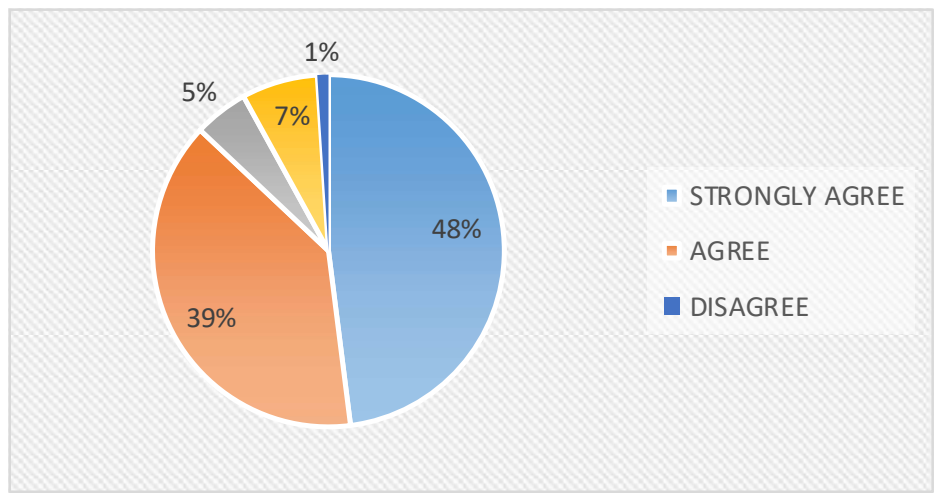

Figure 3.17 displays a situation where consumers depicted the relevance of education to fighting counterfeiting. $48 \%$ of the total responses received from Forty-Eight (08) respondents answered "Strongly Agree" to the statement of education been the way to go in fighting the menace of counterfeiting. Also, Thirty-Nine (39) of the respondents representing 39\% of responses answered "Agree" to the statement. Five (05) respondents representing $5 \%$ of total responses answered "Neutral". Seven (07) other respondents answered "Disagree" whiles One (01) respondent answered "Strongly Disagree".

From the exceeding response to the statement, one can conclusively argue that respondents are in agreement with the statement, hence it is critical for stakeholders in fighting counterfeiting in Ghana to adopt more of an educative approach than a legal one.

Figure 3.18: Are Firms Doing Enough to Prevent Counterfeiting

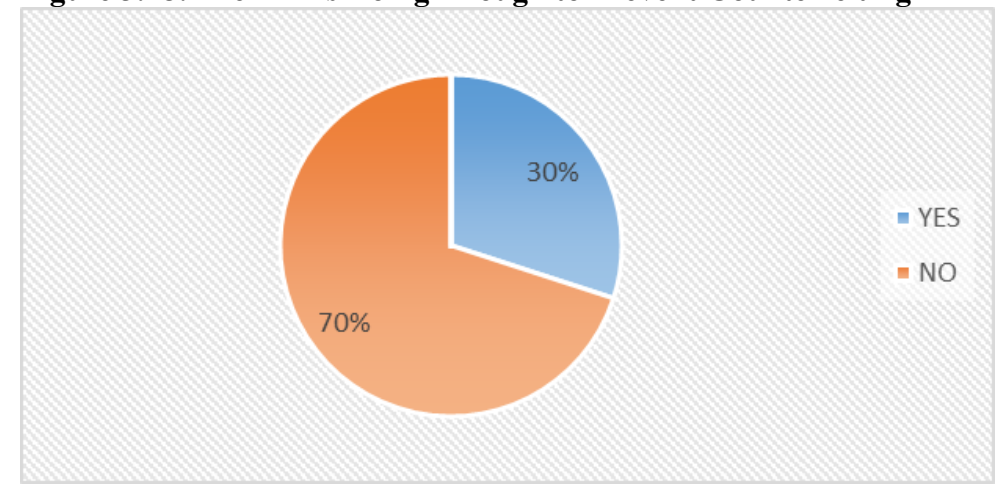


Figure 3.18 depicts the responses from respondents with regards to whether firms are doing enough to curtail counterfeiting. Twenty-Five (25) respondents representing $25 \%$ of responses collated answered "No" to the statement, whiles Seventy-Five (75) respondents representing 75\% answered "Yes". There is a clear majority of respondents who agree with the assertion of firms not putting in place enough measures to curtail counterfeiting. The majority of the respondents answering "YES" to the statement did so with the belief that counterfeiting of fashion accessories leaves in its wake terrorism, child labor, environmental hazards as well as health issues which has to do with uncertified chemicals used in the production of these counterfeits. Furthermore, its telling effects on socio-economic activities is also deemed to be far reaching since extra cost of dealing with environmental and health issues is incurred. In addition high cost of living due to jobs from the authentic accessories manufacturers as well is also a source of worry. Hence, rather than blaming governments for weak legal frameworks as well as porous borders, lack of harmonized policy with neighboring countries; the firms are urged to fight counterfeiting by disrupting the cycle of supply and demand as well as been vigilant with an effective counterfeiting program.

Figure 3.19: Can Counterfeiting Be Stopped

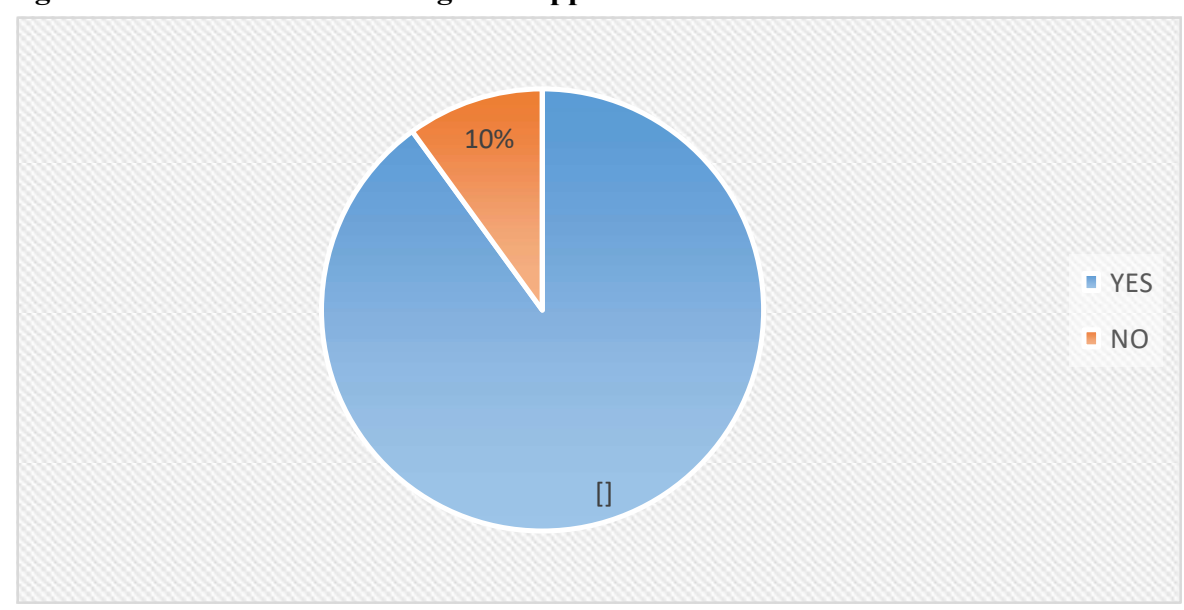

Figure 3.19 depicts the responses of the respondents in relation to whether the possibility of counterfeiting been stopped exist. Seventy-Five (75) respondents representing $90 \%$ of the responses answered "Yes" and TwentyFive (25) respondent representing $10 \%$ of responses answered "No". Thus, with the level of affirmation is an indication that respondents does believe that it is possible to curtail counterfeiting of fashion accessories.

The strategy involves setting up lobbying groups to support the activities of consumer protection organizations, whiles participating in advocacy at grass-root level to help enlighten individuals about the harmful nature of such counterfeited fashion accessories as well as its ability to create monopolies by beating the prices of genuine accessories down.

Also Ghana needs to take count of its anti-counterfeiting laws and streamline them to international standards as well as set up a center which allows firms and government to discuss issues related to counterfeiting. Whiles doing this, it is critical to train government agencies in charge of the anti-counterfeiting in order to provide them with overviews on sector specific best practices as well as the ability to differentiate between authentic and fake fashion accessories.

\section{Discussion}

A number of factors contribute to the influx of counterfeit and sub-standard fashion accessories into Ghana. These include porous borders, inadequate devices or equipment to detect these sub-standard drugs and counterfeit products, inadequate personnel at the border and lack of knowledge and skill and lack of database to track the individual or agency handling the products and non-enforcement of laws. Ghana has legal frameworks that covers the disposal of unwholesome or unauthorized items, such as the (Public Health Act, 2012 Act 851) and Environmental Protection Agency Act, 1994 (Act 490). These frameworks however, do not cover counterfeited or sub-standard fashion accessories. Hence there is no supervision when disposing off such counterfeited fashion accessories, hence causing huge environmental effects.

With regards to porous borders, inadequate personnel and qualified personnel to monitor the borders. Also, the issue of smuggling of the products into the country is as a result of the above stated. Poor inspection of items 
brought into the country is a major issue. As a result of this, officials are unable to properly scrutinize all the products brought to the port for assessment.

The use of insufficient and sophisticated equipment to validate the huge volume of items arriving at the ports of entry is a worry as the situation put unnecessary pressure on limited personnel working at the entry points. The analysis shows that criminal networks and organized crime thrive via counterfeiting of fashion accessories. The items that counterfeiters produce are often substandard, sometimes endangering the lives of those who purchase them. These illicit activities steal market share from legitimate businesses and undermine innovation, with negative implications for economic growth. Bribery associated with counterfeiting and piracy weakens the effectiveness of public institutions at the expense of society at large. Moreover, the savings that consumers may achieve by knowingly purchasing lower-priced counterfeit fashion accessories need to be considered in a broader context. Depending on the fashion accessory, consumers can be worse off. In some cases, consumers seeking to save money may be exposing themselves to health and safety risks when the products concerned are substandard. Governments are also directly affected; tax revenues are foregone and costs are incurred in combating the problem and public institutions are weakened when criminal networks use corruption to facilitate their counterfeiting and piracy activities.

According to the respondents, at the national governmental level, two of the principal challenges in combating counterfeiting of fashion accessories has to do finding ways to enhance enforcement and as well as the need to raise awareness of counterfeiting and piracy issues. More needs to be done to detect and undermine counterfeiting of fashion accessories at the point where infringement originates. Actions are also required to keep the Internet from becoming an even more prominent distribution channel for counterfeit fashion accessories.

The storage and environmentally-sound disposal of expanding quantities of confiscated fashion accessories is seen by respondents as a major cause of environmental pollution since the present a major logistical challenges for national authorities. There is increasing recognition of the need to dispose of these goods in a safe and environmentally-sensitive way. This can be a costly and technically complex undertaking as agreed to by respondents. Minimizing the environmental impact of disposal requires specialized facilities, expertise and high levels of stakeholder collaboration.

One of the key objectives in disposing of seized counterfeited fashion goods is to ensure they are removed from all channels of commerce. While originally conceived as a means to protect originality, increasingly, concerns about the social and environmental impact of these goods are coming to the fore. According to respondent's, safe, secure disposal and storage of these counterfeited fashion goods which is critical to ensure the environmental risks are mitigated and that harmful fashion goods are disposed of in a manner that prevents diversion is lacking. They further stressed that achieving this objective is an increasingly costly and technically complex undertaking.

\section{Conclusion and Recommendations}

This study has provided some answers to why there is an influx of counterfeit fashion accessories into Ghana by identifying the factors behind the menace. What measures agencies have undertaken measures to curb the counterfeit fashion accessories issues in Ghana and the agencies responsible for the implementation of policies, specific roles, prospects and challenges? The findings go to confirm the need to consider strengthening our borders in terms of providing the needed training and equipment or border personnel. The primary data collected confirms that the major stakeholders that should collaborate to address the influx menace are the FDA, EPA, Ghana Textiles and Garments Industry Association and CEPS who need to be provided with the right training and logistics. Again, government' should be interested in strengthening existing agencies in handling fashion and garment products as well as cooperating with other agencies and teaming up with foreign agencies. The establishments of sub-regional office in every region in Ghana will enhance the fight against the influx in the country.

Significant challenges like lack of well-planned orderly operations, inadequate allocation of resources by government, lack of knowledge and skill on the part of officials at the border, difficulty in analyzing passenger's luggage adequately by the CEPS officials should be tackled with all seriousness including collaboration between local enforcing agencies within the country and adequate detective devices at the borders.

Multilaterally, ways to strengthen the existing framework and practices could be explored. Suggestions mentioned in this regard include strengthening civil and criminal remedies to more effectively redress the harm caused to rights holders, expanding border measures and increasing information disclosure. Furthermore at the governmental level, co-operation with industry and among governments could be strengthened. Finally, 
development of effective policies and practices would benefit from more regular assessment, through peer review and related examinations.

While the study has been able to provide insights into the situation, it also notes that the education and provision of information on counterfeited fashion accessories needs to be strengthened. Governments, business and other interested stakeholders could do a far better job collecting and analyzing information that is essential for designing and implementing effective strategies for combating counterfeiting and piracy. This could be done, by including; establishing a common approach for collecting enforcement data; developing a reporting framework to document the effects of counterfeit fashion accessories; making more extensive use of surveys to provide insights into the markets for counterfeit fashion products and education increasing co-operation between governments and business. Improved education and information would enable more far-reaching analyses to be carried out on the magnitude and effects of counterfeiting fashion accessories on economies. In turn, this would provide governments and other stakeholders with a firmer basis for developing more informed and effective policies and programs to combat the illicit practices.

While not all counterfeited items are readily recyclable, in order to fight issues of environmental pollution especially those containing toxic substances respondents suggested the need for government to create an avenue for such seized counterfeited fashion accessories to be dismantled and reused through a recycle system. This is a practical and cost-effective solution for the disposal of counterfeit fashion accessories. Through this counterfeited fashion accessories can be sorted, dismantled and processed for recycling. This approach offers multiple advantages. Such a recycling facility will offer a valuable means of mitigating negative environmental consequences while complying with the necessary requirement to ensure that the counterfeit products do not enter the channels of commerce. It will also offer employment to a large number of unemployed youth. However, to be successful at this, it requires a close coordination and cooperation between customs, member companies and society.

Customers can be an important ally in minimizing sales of counterfeit fashion accessories with all its associated costs. Educating them about the risks of buying from unauthorized sources, and recruit them to join in the effort by reporting counterfeited items is a recommendation geared towards fighting the menace. Also, through the provision of forms or email-based mechanisms for reporting suspected infringement whiles reinforcing the benefits of buying authentic accessories from authorized sellers will go a long way to aid in reducing counterfeiting of fashion accessories.

\section{References}

Aaker, D. A. (1991). Managing brand equity. New York, NY: The Free Press.

Ajzen, I. (2012). Martin Fishbein's legacy: The reasoned action approach. The ANNALS of the American Academy of Political and Social Science, 640, 11-27.

Ajzen, I. (1991). The theory of planned behavior. Organizational Behavior and Human Decision Processes, 50(2), 179-212.

Ang, S. H., Cheng, P. S., Lim, E. A. C., \& Tambyah, S. K. (2001). Spot the difference:Consumer responses towards counterfeits. Journal of Consumer Marketing, 18(3), 219 -235.

Bang, H. K., Ellinger, A. E., Hadjimarcou, J. \& Traichal, P.A. (2000) Consumer concern, knowledge, and attitude toward renewable energy: an application of the reasoned action theory. Psychology \& Marketing, 17(6), 449-468. Retrieved from http://proquest.umi.com.er.lib.k-state.edu/

Bian, X. \& Moutinho, L. (2011). The role of brand image, product involvement, and knowledge in explaining consumer purchase behavior of counterfeits: Direct and indirect effects. European Journal of Marketing, 45(1/2), 191-216.

Bian, X. \& Veloutsou, C. (2007). Consumers' attitudes regarding non-deceptive counterfeit brands in the UK and China. Journal of Brand Management, 14(3), 211-222.

Brucks, M. (1985). The effects of product class knowledge on information search behavior. Journal of Consumer Research, 12 (1), 1-16. Retrieved from http://web.ebscohost.com.er.lib.k-state.edu/

Campbell, D. T., \& Stanley, J. C. (1963). Experimental and quasi-experimental designs for research. $\quad$ Chicago, IL: Rand McNally.

Chang, T. \& Wildt, A. R. (1994). Price, Product Information, and Purchase Intention: An Empirical Study. Journal of the Academy of Marketing Science, 22(1), 16-27. Retrieved from http://proquest.umi.com.er.lib.k-state.edu/

Congressional Research Service (2011) H.R. 2511: Innovative Design Protection and Piracy Prevention Act. GovTrack. Retrieved from http://www.govtrack.us/congress/bills/112/hr2511

Cook, T. D. \& Campbell, D. T. (1979). Quasi-experimentation: Design and analysis for field settings. $\quad$ Chicago, IL: Rand McNally.

Cordell, V. V., Wongtada, N., \& Kieschnick, R. L. (1996). Counterfeit purchase intentions: Role of lawfulness attitudes and product traits as determinants. Journal of Business Research, 35(1), 41-54. Retrieved from http://proquest.umi.com.er.lib.k-state.edu/ Council of Fashion Designers of America. (2013). Design Piracy. Retrieved from http://cfda.com/programs/protecting-intellectual-property 
De Matos, C. A., Ituassu, C. T., Rossi, C. A. V. (2007). Consumer attitudes towards counterfeits: A review and extension Journal of Consumer Marketing, 24(1), 36-47.

Dickson, M. A. (2000). Personal values, beliefs, knowledge, and attitudes relating to intentions to purchase apparel from socially responsible businesses. Clothing and Textiles Research Journal, 18, 19-30.

Eberman, L. E. (2008). Effect of performance feedback on perceived knowledge and likelihood to pursue continuing education. (Doctoral dissertation). Retrieved from ProQuest ETD Collection for Florida International University.

Education Inn of Pakistan. (2009). EduReadings: Tricomponent Attitude Model. Retrieved from http://www.eduinn.pk/2010/06/edureadings-tricomponent-attitude-model.html

Fishbein, M., \& Ajzen, I. (1975). Belief, attitude, intention, and behavior: An introduction to theory and research. Reading, Massachusetts: Addison-Wesley Publishing Company.

Grossman, G. M., \& Shapiro, C. (1988). Foreign counterfeiting of status goods. Quarterly Journal of 103(1), 79-100. Retrieved from http://web.ebscohost.com.er.lib.k-state.edu/

Ha, S., \& Lennon, S. J. (2006). Purchase intent for fashion counterfeit products: Ethical ideologies, ethical judgments, and perceived risks. Clothing and Textiles Research Journal, 24(4), 297-315.

Hanzaee, K. H. \& Ghafelehbashi, S. (2012). The role of product involvement, knowledge, and perceptions in consumer purchase behavior of counterfeits: Perspective Islamic Country. Journal of Basic and Applied Scientific Research, 2(1), 418-425.

Hunt, S. D., \& Vitell, S. J. (2006). The general theory of marketing ethics: A revision and three questions. Journal of Macromarketing, 26(2), 143-153.

International Anti-Counterfeiting Coalition. (n.d). About counterfeiting. Retrieved from https://iacc.org/aboutcounterfeiting/ International Anti-Counterfeiting Coalition. (n.d).

The truth about counterfeiting. Retrieved from https://iacc.org/about-counterfeiting/the-truth-about-counterfeiting.php

International Herald Tribune. (2007). Counterfeit goods are linked to terror groups. Retrieved from http://www.nytimes.com/2007/02/12/business/worldbusiness/12iht-fake.4569452.html

Investigative Consultants. (n.d.). Welcome to Investigative Consultants. Retrieved from http:/www.investigativeconsultants.com/ Kim, H., \& Karpova, E. (2010). Consumer attitudes toward fashion counterfeits: Application of the theory of planned behavior. Clothing and Textiles Research Journal, 28(2), 79-94.

Kim, J. E., Cho, H. J., \& Johnson, K. K. P. (2009). Influence of moral affect, judgment, and intensity on decision making concerning counterfeit, gray-market, and imitation products. Clothing and Textiles Research Journal, 27(3), 211-226.

Kirk, R. E. (2009). Experimental design. In R. E. Millsap \& A. Maydeu-Olivares (Eds.), The SAGE handbook of quantitative methods in psychology. (pp. 23-45)

Koklic, M. K. (2011). Non-deceptive counterfeiting purchase behavior: Antecedents of attitudes and purchase intension. Journal of Applied Business Research, 27(2), 127-137.

Kozar, J. M., \& Marcketti, S. B. (2008). Counterfeiting: the importance of education to ethical decision making. Journal of Family and Consumer Sciences, 100(4), 49-50.

Kozar, J. M., \& Marcketti, S. B. (2011). Examining ethics and materialism with purchase of counterfeits. Social Responsibility Journal, 7(3), 393-404.

Laerd (2012). Internal Validity.

Leamy, E. \& Weber, V. (2010, January 27). Fake fragrances: What is really in them? ABC Good Morning America. Retrieved from http://abcnews.go.com/GMA/ConsumerNews/counterfeit-perfumes/story?id=9670448

Madden, T. J., Ellen, P. S., \& Ajzen, I. (1992). A comparison of the theory of planned behavior and the theory reasoned action. Personality \& Social Psychology Bulletin, 18(1), 3-9.

Marcketti, S. B., \& Parsons, J. L. (2006). Design piracy and self-regulation: The Fashion Originators' Guild of America, 1932-1941. Clothing and Textiles Research Journal, 24(3), 214-228.

Marcketti, S. B., \& Shelley, M. C. (2009). Consumer concern, knowledge and attitude towards counterfeit apparel products. International Journal of Consumer Studies, 33, 327-337. 